Macedonian Pharmaceutical Bulletin, 66 (Suppl 1) 157 - 158 (2020)

Online ISSN $1857-8969$

UDC: $615.014 .4: 551.581 .2$

DOI: 10.33320/maced.pharm.bull.2020.66.03.078

Short communication

\title{
On-going stability studies in climatic zones III and IV
}

\author{
Milena Nanov*, Nadica Boeva, Kristina Jozikj, Ana Vavlukis, Jana Pop Nikolova, \\ Stefan Davidovski, Sanja Despotovska
}

\author{
Alkaloid AD-Skopje, Pharmaceutical, Chemical and Cosmetics Industry, \\ blvd. Aleksandar Makedonski 12, 1000 Skopje, Republic of North Macedonia
}

\section{Introduction}

The climate is different in all countries in the world. Stability studies of the drug product and drug substances should be done according to the climatic conditions of the country. Stability testing is a routine procedure that is performed to provide evidence on how the quality of a drug substance or drug product varies with time under the influence of variety of parameters, and to establish a re-test period for the drug substance or a shelf life for the drug product and recommended storage conditions.

Any physical, chemical, microbiological or change in container closure system in the product, potentially impact the efficiency and integrity of the final product and may therefore directly or indirectly impact patient's health.

\section{Materials and methods}

There are several regulations and guidelines for stability studies of drug products and drug substances. According to the World Health Organization for stability testing of drug product and drug substances, the climate of the world is derived into five different zones: Zone I: temperate; Zone II: Mediterranean/subtropical; Zone III: hot and dry; Zone IVa: hot humid/tropical and Zone IVb: hot/higher humidity. At a WHO meeting entitled "Stability Studies in a Global Environment", held in
Geneva, December 2004, where discussions regarding stability testing for registration in climatic zone III or IV caused confusion and uncertainties, were adopted changes to stability testing requirements at an international level resulting in the following stability long-term study conditions for hot and humid climates (WHO Technical Report Series, no. 1010, Annex 10):

- $30^{\circ} \mathrm{C} / 65 \%$ RH e.g. WHO, ICH, SADC, GCC, Brazil

- $30^{\circ} \mathrm{C} / 70 \%$ RH e.g. EHO previous, Cuba, Brazil previous

- $30^{\circ} \mathrm{C} / 75 \%$ RH e.g. ASEAN

These changes were based on new calculations and discussions where some countries in climatic zone IV expressed their wish to include a larger safety margin for medicinal products to be marketed in their region than previously foreseen in $\mathrm{ICH}$ Q11F (Stability Data Package for Registration Applications in Climatic Zone III and IV) (ICH guideline Q1A (R2)).

\section{Results and discussion}

As a consequence, several countries and regions have revised their own stability testing guidelines, defining up to $30^{\circ} \mathrm{C} / 75 \%$ as the long-term storage conditions for hot and humid regions. The ICH Steering Committee has decided to withdraw ICH $\mathrm{Q} 1 \mathrm{~F}$ and to leave the definition of storage conditions

\footnotetext{
*mstrezovska@alkaloid.com.mk
} 
in Climatic Zones III and IV to the respective regions and the WHO. In assessing the impact of the withdrawal of $\mathrm{ICH}$ Q1F on intermediate testing conditions defined in ICH Q1A (R2), a decision was made to retain $30^{\circ} \mathrm{C} / 65 \%$. However, regulatory authorities in the $\mathrm{ICH}$ regions have agreed that the use of more stringent humidity conditions such as $30^{\circ} \mathrm{C} / 75 \%$ will be acceptable, if the applicant decide to use them (ICH guideline Q1A (R2), 2003).

\section{History of discussions}

At the $40^{\text {th }}$ WHO Expert Committee Meeting, October 2005, the Committee determined that the WHO stability guidelines should be amended to reflect conditions for Zone III and IV as follows:

- Zone III: $30^{\circ} \mathrm{C} / 35 \% \mathrm{RH}$

- Zone IVa: $30^{\circ} \mathrm{C} / 65 \% \mathrm{RH}$

- Zone IVb: $30^{\circ} \mathrm{C} / 75 \% \mathrm{RH}$

Further it was resolved that each individual Member State within the former Zone IV will need to classify itself as Zone IVa or Zone IVb.

On the $37^{\text {th }}$ Report of The WHO Expert Committee on Specifications for Pharmaceutical Preparations, Geneva, 22-26 October 2001, it was discussed and adopted the recommended modification of storage conditions published in WHO guidelines for stability testing of pharmaceutical products containing well-established drug substances in conventional dosage forms to read $30^{\circ} \mathrm{C}( \pm 2)$ and $65^{\circ} \mathrm{C}( \pm 5 \%) \mathrm{RH}$ for real-time stability studies destined for climatic zone IV. It was also agreed that where special transportation and storage conditions were identified as being outside these criteria, additional study data supporting these conditions should be available. For countries where certain regions are situated in Zone III or IV, and also with a view to the global market, it is recommended that stability testing programs should be based on the conditions corresponding to climatic Zone IV. In a stability study, the effect of variations in temperature, time, humidity, light intensity and partial vapor pressure on the product in question are investigated.
The effective or mean kinetic temperature reflects the actual situation better than the measured mean temperature; a product kept for 1 month at $20^{\circ} \mathrm{C}$ and 1 month at $40^{\circ} \mathrm{C}$ will differ from one kept for 2 months at $30{ }^{\circ} \mathrm{C}$ (Markens, 2009; WHO Technical Report Series, no. 1010, Annex 10, 2018).

Moreover, the storage conditions are often such that the temperature is higher than the average meteorological data for a country would indicate.

\section{Conclusion}

A successful stability study will establish the shelf-life date on the drug product, the retest period of a drug substance and appropriate storage conditions-but that's not all. A successful stability study must also ensure that patients receive a safe and effective medicine. To ensure that this happens, drug manufacturers need to thoroughly follow regulations and guidelines.

\section{Acknowledgement}

The author would like to thank Alkaloid ADSkopje, Pharmaceutical, Chemical and Cosmetics Company, for support, comments and suggestions made during the writing of this paper.

\section{References}

International Council for Harmonization of Technical Requirements for Pharmaceuticals for Human Use; ICH guideline Q1A (R2) Stability testing of new drug substances and products, Step 5, August, 2003.

Markens, U., 2009. Conducting stability studies-recent changes to climatic zone IV. Life science Technical Bulletin 13.

WHO Technical Report Series, no. 1010, 2018. Annex 10 Stability testing of active pharmaceutical ingredients and finished pharmaceutical products. 